\title{
Validation of chicken-specific pro-angiogenic growth factors three-dimensional structures and analysis of their role in high molecular weight heparin-induced angiogenesis
}

Reji Manjunathan ( $\sim$ rejimanjunath@gmail.com )

University of Madras

Vijayalakshmi Periyaswami

Holy Cross College

Malathi Ragunathan

University of Madras

Research article

Keywords: High-molecular weight heparin - HMWH, Fibroblast growth factor - FGF2, Matrix metalloproteinase 2-MMP2, Molecular docking, Angiogenesis

Posted Date: August 16th, 2021

DOI: https://doi.org/10.21203/rs.3.rs-547548/v1

License: (c) (1) This work is licensed under a Creative Commons Attribution 4.0 International License.

Read Full License 


\section{Abstract \\ Background}

- High-molecular weight heparin (HMWH), a molecule which is extensively in use as an anticoagulant shows concentration-dependent angiogenic and anti-angiogenic potential. Based on the concentration, $\mathrm{HMWH}$ can bind with both angiogenic and anti-angiogenic factors and exerts diverse effect. Our earlier data suggested that HMWH (15 kDa) can induce concentration-dependent neovascularization on chicken chorioallantoic membrane (CAM). The diffusion pattern of HMWH through various layers of CAM supports its internalized action with the various cellular components of angiogenesis. So far, no studies have reported the interactive potential of $\mathrm{HMWH}$ with various pro-angiogenic growth factors under physiological conditions. Hence, we aimed to find the transcription level interaction of HMWH with major pro-angiogenic growth factors. In connection to the research, for the first time, we validated the threedimensional structures of chicken-specific pro-angiogenic growth factors such as FGF2, MMP2, MMP9, NOS3, VEGF A, and VEGF $\mathrm{C}$ to find the binding affinity of HMWH with the core-functional units of these growth factors.

\section{Methods}

- CAMs are incubated with 50,100, and $150 \mu \mathrm{M}$ concentration of HMWH. Changes in the transcription level of specified pro-angiogenic growth factors are analyzed by semi-PCR method. The functional aspects of these molecules are identified with zymogram and immunohistochemical approaches. Scanning electron microscopic technique is applied to find the morphological changes on CAM under HMWH incubation. Three-dimensional structure validation and molecular docking are performed using the SWISS-MODEL web server and AutoDock vina-PyRx software version 8.0.

\section{Results}

- HMWH can enhance the transcription level of major pro-angiogenic growth factors with a significant impact on FGF2 and MMP2 under $100 \mu \mathrm{M}$ concentration. The in-silico analysis reveals that HMWH shows a higher binding affinity with FGF2 followed by MMP2, MMP9, NOS3, VEGF A, and VEGF C, respectively.

\section{Conclusion}

- The combined results from the experimental and in-silico analysis reveal that HMWH can interact with pro-angiogenic growth factors under micromolar concentration in physiological conditions while inducing angiogenesis. This observation further supports the therapeutic benefits of $\mathrm{HMWH}$ as an angiogenic factor under micromolar concentration. 


\section{Background}

The process of angiogenesis is highly dynamic and is mediated through a complex multistep process by various cellular components. Angiogenesis plays a central role in various physiological and pathological processes such as foetal development, wound healing, and tissue repair after surgery, cancer, and various inflammatory diseases [1]. Proteins such as basic fibroblast growth factor 2 (bFGF2) and vascular endothelial growth factor (VEGF) are associated with endothelial cell (EC) growth and differentiation while on angiogenesis [2, 3]. High-molecular-weight Heparin $(\mathrm{HMWH})$ is a highly sulfated glycosaminoglycan carbohydrate molecule and is commonly used to prevent blood clots in many medical conditions because of its high negative charge density $[4,5]$. HMWH binds with both angiogenic and anti-angiogenic growth factors and exerts diverse effects on angiogenesis based on the concentrations and the molecular weight [6]. In the cellular system, the Heparin, which is located at the extracellular matrix (ECM), acts as a reservoir for angiogenic growth factors and will sustain a long-term stimulation of endothelial cells in support of neovascularization [7].

In our earlier study, we reported that the high molecular weight heparin (UFH, $15 \mathrm{kDa}$ ) could induce the formation of capillary-like tubular structures on the chick chorioallantoic membrane vascular model (CAM) and could establish concentration-dependent angiogenic ability [4]. While some reports indicated that the low molecular weight heparin sulfate $(\mathrm{LMWH})$ was found to inhibit angiogenesis on CAM vascular model [8]. The CAM is a simple, highly vascularized extra embryonic membrane that performs multiple embryonic development functions [9]. For more than two decades, the CAM model uses a robust experimental platform to evaluate the angiogenic and anti-angiogenic potential of many natural and synthetic compounds $[10,11,4]$.

In the present study, we mainly aim to analyze the interactive nature of $15 \mathrm{kDa}$ molecular weight heparin with some of the significant pro-angiogenic growth factors such as FGF2, MMP2, MMP9, NOS3, VEGF A, and VEGF $C$ in order to prove its angiogenic potential using CAM model. As a preliminary step, for the first time, we validated the three-dimensional structure of those mentioned above chicken-specific proangiogenic molecules using the SWISS-MODEL web server and Global Model Consistency Estimation (GMQE) and Qualitative Model Energy Analysis (QMEAN) methods. Molecular docking analysis with the help of the Autodock module available in PyRx Version 0.8 software is performed to find out the binding efficacy of these pro-angiogenic molecules with the core functional unit of the high molecular weight heparin. Further, we validated the in-silico inferences using CAM vascular model with the help of molecular, protein, and microscopic methodologies.

\section{Results}

\section{Target-template sequence alignment and homology modeling of the targeted sequences}

3D structures of chicken-specific pro-angiogenic growth factors such as

FGF2, MMP2, MMP9, NOS3, VEGF A, and VEGF C are built using the SWISS-MODEL server. The templates 
of the specific proteins were selected based on the sequence identity. The template for FGF2 (PDB id: 1114 shows $91.61 \%$ sequence identity), MMP2 (PDB id: 1 CK7 shows $85.42 \%$ sequence identity), MMP9 (PDB id: 1 CK7 shows $49.83 \%$ sequence identity), NOS3 (PDB id: $3 E A H$ shows $80.42 \%$ sequence identity) VEGF A (PDB id: 1 WQ8 shows $51.52 \%$ sequence identity), and VEGF C (PDB id: 2 XV7 shows $59.62 \%$ sequence identity) are selected respectively. The alignments between the target and the template proteins are shown in supplementary files (Supplementary figure 1 and 2). The GMQE value and the QMEAN score of all the proteins indicate that the modeled structure is reliable and has a good quality. The modeled structures of all the proteins are visualized using chimera.

\section{Structure validation of modeled protein}

The Ramachandran plot statistics implied that the modeled 3D structure of FGF2, MMP2, MMP9, NOS3, VEGF A, and VEGF C has $93.7 \%, 88.9 \%, 89.1 \%, 93 \%, 96.6 \%$, and $91 \%$ residues in the most favored regions of the Ramachandran plot. Thus, this process validated that the modeled 3D structures are of good quality (Figure 1).

\section{Molecular docking}

The molecular docking technique aims to find the contact between the Heparin, the target molecule, with the chosen target receptors based on the binding energy. The ligand strictly binds in the cavity of the unique target molecule if it exhibits the lowest amount of binding energy. In the present study, Heparin showed the best binding efficacy with the selected proteins. Hydrogen bonding between the ligand and the proteins raises the specificity of the contact and therefore provides the molecular recognition and strength of interaction. In the present analysis, Heparin formed more hydrogen bonds within the binding site of the selected protein molecules and shows that it has a solid binding interaction with the selected pro-angiogenic growth factors. The free binding energy requirement for all the studied protein-ligand complex combinations is calculated and given in table 3. Among the six analyzed combinations, Heparin shows the most significant binding affinity with the FGF2 molecule than the others. Also, it shows free binding energy of $-12.5 \mathrm{Kcal} / \mathrm{mol}$ with the formation of 6 hydrogen bonds. The Heparin binds with MMP2 with a free binding energy of $-10.4 \mathrm{Kcal} / \mathrm{mol}$ with 6 hydrogen bonds and MMP9 with a free binding energy of $-10.1 \mathrm{Kcal} / \mathrm{mol}$ with 9 hydrogen bonds respectively. While considering the other molecules, the Heparin shows free binding energy of $-9.3 \mathrm{Kcal} / \mathrm{mol}$ with 6 hydrogen bonding with NOS3, and a free binding energy of -8.6 and $-8.2 \mathrm{Kcal} / \mathrm{mol}$ with VEGF $A$ and VEGF $C$ with the help of 7 and 5 hydrogen bonds respectively. The 3D interaction of the protein-ligand complex is graphically represented in figure 2 . The data shows that the ligand molecule, Heparin, could interact with the significant pro-angiogenic growth factors and thereby induces the mechanism of angiogenesis mainly through the functional involvement of FGF2, MMP2, and MMP9.

\section{Heparin induces neovascularization on CAM vascular bed}

The CAM assay is performed to visualize the impact of Heparin on angiogenesis using CAM vascular bed. Figure 3 represents the images of the CAM vascular bed recorded at 0 and 72 hours of 
incubation. Control CAM shows a slow and steady growth of allantoic vessel formation around the sponge. While the CAMs incubated with three various concentrations of heparin show rich vascular zone around the sponge. Among the analyzed concentrations, the CAM incubated with $100 \mu \mathrm{M}$ heparin shows a distinct spoke wheel pattern of vessel growth around the gelatine sponge due to numerous allantoic blood vessel sprouting. The images also indicate that the neovascularization effect of $100 \mu \mathrm{M}$ concentration of Heparin is comparatively higher than the other two studied concentrations. The inference is supported by the skeletonized prune images obtained from Angioquant software in which the blood vessels are marked as red lines. Hence, the data indicate that Heparin could exhibit dose-dependent neovascularization potential.

\section{Heparin up-regulates the molecular level expression of pro-angiogenic growth factors}

The potential of Heparin to enhance the molecular level expression of major pro-angiogenic growth factors such as VEGF 160 (VEGF A), VEGF 190 (VEGF C), FGF2, MMP2, MMP9, and NOS3 were analyzed by semi-quantitative Reverse Transcriptase PCR method. The intensity of the bands is measured as relative OD and is given in Figure 4. The mRNA expression level of analyzed pro-angiogenic growth factors are increased upon heparin incubation. Among the studied concentrations, $100 \mu \mathrm{M}$ concentration of heparin exhibit the most significant impact. When compared to the control value (standardized as one fold), the level of mRNA expression of FGF2 increased significantly up to 3 fold, MMP2 up to 2.8 fold, MMP9 up to 2.4 fold, NOS3 up to 2.2, VEGF A up to 1.8 fold, and VEGF C up to 1.6 fold under $100 \mu \mathrm{M}$ concentration of Heparin ( $\left.{ }^{*} p<0.001\right)$. It is also noted that the mRNA level expression of FGF2 and MMP2 has been increased significantly even at 50 and $150 \mu \mathrm{M}$ concentrations of Heparin significantly $\left({ }^{*} \mathrm{p}<0.001\right)$. The mRNA level expression of MMP9, NOS3, VEGF A, and VEGF $\mathrm{C}$ is found to increase at $150 \mu \mathrm{M}$ concentration of Heparin significantly ( ${ }^{*} p<0.001$, and $\left.\# p=0.001\right)$. The PCR data support the fact that Heparin could accelerate the transcriptional rate of the pro-angiogenic growth factors while exerting its angiogenic potential. Though Heparin is found to increase the transcription level of all the studied proangiogenic factors, it is mainly found to increase FGF2 and MMP2. The inference also shows that $100 \mu \mathrm{M}$ concentration of Heparin shows the maximum angiogenic response among the analyzed concentrations.

\section{Heparin raises the basement membrane degradation by accelerating MMP2 function}

The potential of Heparin to initiates the new blood vessel formation is measured in turns of its ability to accelerate the gelatinase activity of MMP2 to degrade the extracellular matrix in favor of endothelial cell proliferation and migration while on the neovascularization process. The gelatinase activity of MMP2 on CAM vascular bed up on heparin incubation is confirmed by the zymogram method, which is indicated as a white band against the blue background, and the effect is compared with control (1X PBS). The gelatinase activity of MMP2 is increased under all studied concentrations (Figure 5, a). The rate of MMP2 gelatinase activity under Heparin is measured in terms of OD and is graphically represented in figure 5.b. The OD value for control CAM is taken as one. Among the analyzed concentrations, both the 100 and $150 \mu \mathrm{M}$ concentrations of Heparin show the maximum gelatinase 
activity significantly ( $\left.{ }^{*} p<0.001\right)$ and are 1.13 and 1.06 fold greater than the control effect, respectively. Thus, the gelatine zymogram analysis shows that the Heparin can induce new blood vessel formation by increasing the degradation of extracellular matrix to favor ECs proliferation and migration, and the effect is significant under $100 \mu \mathrm{M}$ concentration.

\section{Heparin increases the expression of FGF2 and MMP2 at the protein level}

From the in silico and the molecular profiling analysis, we found that the Heparin-mediated angiogenic process mainly operates through the operational support of FGF2 and MMP2 than the other studied proangiogenic factors. While performing immunohistochemical analysis, we try to identify both FGF2 and MMP2 at the protein level to confirm the idea. Figure 6 represents the immunohistochemical expression of FGF2 and MMP2 on CAM vascular bed. The images indicate that the CAM tissue incubated with 100 $\mu \mathrm{M}$ concentration of Heparin shows more FGF2 in the chorionic layer, majorly at the stromal region than the control CAM (Figure 6.B). The large blood vessels of the same CAM tissue also show more vessel ECs with FGF2 expression located beneath the chorionic layer. The control CAM shows the presence of more FGF2 by those ECs trapped at the small vessels (Figure 6. A). In MMP2 expression, the control CAM vascular bed shows a substantial presence of MMP2 throughout the chorionic layer (Figure 6.C). The CAM incubated with $100 \mu \mathrm{M}$ concentration of Heparin shows more MMP2 expression throughout the chorionic layer and at the sub-epithelial capillary network region as a requirement for basement membrane degradation for sprouting benefit of new tubule like structures (Figure 6.D). The data emphasize that Heparin can induce angiogenesis by enhancing the functional properties of FGF2 and MMP2. These changes, in turn, favor the Heparin-induced microvascular ECs migration, proliferation, and differentiation. FGF2 presence at the vessel endothelium also indicates that the Heparin could accelerate the EC activation and sprout to induce new vessels sprouting from the major ones.

\section{Heparin changes the microvascular environment of the CAM vascular bed}

Observing the changes in the SEM images of the microvascular environment of the CAM vascular bed, we try to confirm the angiogenic potential of Heparin. Figure 7 represents the SEM images of control CAM and CAM incubated with $100 \mu \mathrm{M}$ concentration of Heparin. CAM vascular bed incubated with Heparin shows many sprouted and elongated vessels (black arrows) with a few angiogenic holes (yellow arrows). The capillaries are visible as septum-like structures without circular post at the vicinity of the giant vessel (red arrow) because of long tissue septa from the capillary plexus that separates the blood vessels. On the contrary, control CAM shows a flat capillary network at the outer structure with small blood vessel bulges (green arrows). Angiogenic holes (yellow arrows) are also visible as an indication of intussusceptive angiogenesis, which usually happens at the development of CAM vasculature. Thus, SEM image analysis supports the fact that Heparin can induce sprouting of new blood vessels from the main vessel through ECs elongation and migration.

\section{Discussion}


Our earlier study reported that HMWH (15 kDa) could exhibit concentration-dependent neovascularization potential on CAM vascular bed. The molecule significantly induced the vessels' growth and was found to increase the thickness of the vascular bed due to enhanced neovascularization at the area of incubation under $100 \mu \mathrm{M}$ concentration. In that research, we also pointed out the diffusion pattern and internalized action of Heparin as a preliminary observation which can further flag the interactive potential of Heparin with many angiogenic growth factors [4]. Hence, in the present study, we aimed to validate our earlier hypothesis that $\mathrm{HMWH}$ could regulate angiogenesis through interacting with angiogenic growth factors. For the first time, we evaluated the transcription level of certain pro-angiogenic growth factors and analyzed the angiogenic response of HMWH through various methodologies using CAM vascular model.

We validated the three-dimensional structure of certain chicken-specific pro-angiogenic growth factors such as FGF2, MMP2, MMP9, NOS3, VEGF A, and VEGF C. The in-silico model evaluation provided a primary outlook about the degree of binding affinity of Heparin with the specified pro-angiogenic growth factors. The data indicated that among the analyzed pro-angiogenic molecules, Heparin shows the maximum binding affinity towards FGF2 protein. Heparin also shows greater binding affinity with MMP2, followed by MMP9, NOS3, VEGF A, and finally with VEGF C. The in-silico analysis highlighted that $15 \mathrm{kDa}$ HMWH was found to induce angiogenesis mainly through FGF2 mediated cellular activities, which is further enhanced by the interactions of MMP2, MMP9, and NOS3. Heparin was also found to interact with the most common angiogenic factors such as VEGF A and VEGF C. However, the effect is assumed to be comparatively lesser than that of FGF2, MMP2, MMP9, and NOS3 mediated angiogenic process, at least in our in-silico evaluation.

Heparin is known for its diverse effect on angiogenesis [21, 22]. Heparin can bind with vascular cells such as ECs and smooth muscle cells and regulate the various angiogenic processes. Heparin interaction with angiogenic growth factors depends on the distribution of sulfate groups and the length of the distinct oligosaccharide sequences [23]. Our mRNA expression study reveals that HMWH shows dose-dependent interaction with major pro-angiogenic growth factors. Among the studied concentrations $(50,100,150$ $\mu \mathrm{M}), 100 \mu \mathrm{M}$ concentration of Heparin exerts its maximum potential by significantly increasing the mRNA level expression of all pro-angiogenic growth factors. The transcription level of FGF2 and MMP2 has increased significantly under all three concentrations of $\mathrm{HMWH}$ with a greater transcription rate under $100 \mu \mathrm{M}$ concentration. Numerous pieces of evidence implicated that heparin sulfate glycosaminoglycan can enhance FGF2 expression and can regulate FGF2 mediated angiogenic signaling [24, 25, 26, and 27]. FGF2 directly affects angiogenesis by induction of tubulogenesis and migration of endothelial progenitor cells and affects the expression of several chemo cytokines such as VEGFs [28]. Our study found that the micromolar concentration of HMWH can accelerate the gene transcription level of FGF2 than any other analyzed growth factors. MMPs are grouped under significant endopeptidases to degrade basement membrane components and extracellular matrix [29]. Among the many zinc-dependent endopeptidases, the MMP2 (Gelatinase A, $72 \mathrm{kDa}$ ) and MMP9 (Gelatinase B, 92-225 kDa) play a significant role in the induction of angiogenesis. Information about HMWH interaction with MMP2 and MMP9 is in paucity. It is noticed that Heparin increases the gelatinase activity of MMP9 than MMP2 [30]. Stimulation of platelets and other cell lines with HMWH was found to increase the mRNA level of MMP9. Our semi-PCR data 
indicates that after FGF2, HMWH could accelerate the transcription level of MMP2 irrespective of the concentration and is in agreement with the previous report [31]. The zymogram data also supports the same observation. Though Heparin could enhance the transcription of MMP9 significantly, the effect is noticeable only under 100 and $150 \mu \mathrm{M}$ concentration.

Nitric Oxide (NO) produced from nitric oxide synthase (NOS3) is a vital angiogenesis mediator and is found to regulate the VEGF-based angiogenic process in ECs [32]. To exert its biological action on vascular smooth muscle cells, Heparin required the support of eNOS [33]. Previously it has been reported that Heparin could increase NOS3 activity in bovine ECs without knowing the actual mechanism behind the action [34]. Upchurch Gr Jr et al. reported that a high concentration of heparin decrease NOS3 [35]. Our molecular profiling data also support the same observation. We found that the transcription level of NOS3 mRNA increased significantly under the micromolar concentration of Heparin with maximum effect with $100 \mu \mathrm{M}$ concentration. VEGF is considered as one of the essential pro-angiogenic factors having a mitogenic and anti-apoptotic effect on ECs. VEGF regulates angiogenesis through the enhancement of vascular permeability and ECs migration [23]. HMWH has a strong affinity with VEGF A than any other VEGF forms [36]. It was reported that Heparin could regulate the functional properties of VEGF A (VEGF 165). Very low and very high concentrations of Heparin inhibits VEGF A mediated angiogenic response in in vitro condition $[37,38]$. In this particular study, we observed that the transcription level of VEGF A had been enhanced under 100 and $150 \mu \mathrm{M}$ concentrations than the VEGF C. The gene transcription pattern follows the binding efficacy pattern of in-silico analysis. Thus, our data emphasize that $15 \mathrm{kDa} H \mathrm{HWH}$ induces angiogenesis primarily through FGF2 and MMP2 and is accelerated with the support of MMP9, NOS3, VEGF A, and VEGF C.

The CAM consists of a dense vascular network, and this extra embryonic membrane physiologically serves as a respiratory organ for the embryo until it hatches. Because of its extensive vasculature, CAM allows having a large-scale screening of chemicals impact on angiogenesis with the easy application of many experimental methodologies [10]. One of the main advantages of CAM is that the impact of the test materials on angiogenesis can be visualized directly and could validate further with the aid of many microscopic applications [4]. In this particular study, we analyzed the changes in the vascular morphological structure of the CAM under HMWH incubation. We found that the HMWH can induce neovascularization by employing many numerous small vessels from the main large blood vessels. Involvement of the specific growth factors such as FGF2 and MMP2 on HMWH induced angiogenesis is documented by identifying these molecules' protein level expression on CAM. The data shows that the expression of these proteins is more prominent in CAM incubated with HMWH. The FGF2 expression is evident in those ECs trapped at the main blood vessels and in between the septum of the main vessels, in which the sprouting of new blood vessels occurs. The MMP2 expression is found to locate more at the sub-epithelial capillary network region as a requirement for the basement membrane degradation to sprout tubule-like structures.

\section{Conclusion}


The results obtained from our combined experimental and molecular modeling approach provide a piece of precious information on how HMWH ( $15 \mathrm{kDa}$ ) interacts with various pro-angiogenic growth factors under various concentrations while inducing angiogenesis. The neovascularization potential of $\mathrm{HMWH}$ is concentration-dependent and exerts its maximum angiogenic potential at micromolar concentration. $\mathrm{HMWH}$ can accelerate the transcription level of most known pro-angiogenic growth factors, but it mainly activates the angiogenic process through FGF2 and MMP2 significantly. By establishing a threedimensional molecular structure of chicken-specific pro-angiogenic growth factors, we provided insight into the binding efficacy of HMWH with various angiogenic molecules. The data support a novel mechanism by which HMWH can induce neovascularization and highlights the application of this molecule for the prophylaxis of various pathological conditions that arise due to insufficient healthy vasculatures such as wound healing.

\section{Materials And Methods}

\section{Materials}

Fertilized white leghorn chicken eggs are purchased from Tamil Nadu Poultry Research Station, Madras Veterinary University, Nandanam, Tamil Nadu, India. Gelatine sponges are purchased from Jhonson \& Jhonson Pvt Lmtd, India. Paraffin film, wax, TRIzol reagent, agarose, and EtBr are purchased from Sigma, Aldrich, USA. High molecular weight Heparin purchased from CALBIOCHEM, USA (Product No. 375054). ImProm-1 $11^{\text {TM }}$ Reverse Transcriptase kit and GoTaq Green Master Mix PCR amplification kit were from Promega, USA, Oligo (dt) of length 18-meres from Eurofins, mwg operon, Germany, Random hexamers from MP Biomedicals, USA. All primers are purchased from Bioserve, India. DNA ladders purchased from Invitrogen, USA. DAB system purchased from Bangalore Genei, India. Bradford reagent and FITC (Goat ant-rabbit IgG were from Bangalore Genei, India. SDS-PAGE Standards marker purchased from BIO-RAD, CANADA. Rabbit polyclonal FGF2 and MMP2 are a kind gift from Dr. Li Haiqing, MD, Ph.D., Technology transfer specialist, National Cancer Institute, Rockville, USA. Unless otherwise specified, all other common reagents and chemicals are purchased from Sigma, Aldrich, USA.

\section{Methods}

\section{Selection of template for homology modeling}

The experimental crystal structures of major chicken-specific pro-angiogenic growth factors such as FGF2, MMP2, MMP9, NOS3, VEGF A, and VEGF C are not available in Protein Data Bank (PDB). Hence, we try to validate the crystal structures of mentioned chicken-specific pro-angiogenic growth factors for the time. The UniProt Knowledgebase (UniProtKB) sequence of these proteins is obtained with accession number and is followed as FGF2-P48800, MMP2-Q90611, MMP9-A0A3Q2U2B5, NOS3-H9CZQ2, VEGF A P67964, and VEGF C- E1C7C6, respectively [12]. For building an appropriate query sequence and sequence identity models, the protein IDs were up-loaded in the webserver of SWISS-MODEL [13]. A Global Model Consistency Estimation (GMQE) and Qualitative Model Energy Analysis (QMEAN) have 
been chosen to obtain the most accurate 3D structure for each protein $[14,15]$. The modeled structures are visualized by using chimera [16].

\section{Structure validation of modeled protein}

The quality of the modeled 3D structures created through SWISS-MODEL was verified using PROCHECK. The PDB file formats of the modeled structure of all the proteins were downloaded and submitted to the SAVS server to obtain both the Ramachandran plot and the Ramachandran plot statistics. The Ramachandran plot is an experimental structure. The statistics of the Ramachandran plot include details on the total number of residues of amino acids present at the favorable, permitted, and disallowed regions [17].

\section{Molecular Docking Analysis}

\section{Protein preparation}

The homology modeled 3D structure of the target proteins, such as FGF2, MMP2, MMP9, NOS3, VEGF A, VEGF C, are downloaded from SWISS-MODEL in its PDB format. The modeled protein structures were defined as receptors and were prepared by the computation of Gasteiger charges, with the polar hydrogens and merging of the nonpolar hydrogens using AutoDock Tools 1.5.6. The structures are then saved for input into PyRx in the PDBQT file format.

\section{Ligand Preparation}

The structure of Heparin was downloaded from the PubChem Compound Database in the Spatial Data File (SDF) format and converted into the PDB file format using the Online Smile Translator. First, the ligand structure was stored for input to AutoDock vina-PyRx as a pdf file format, and then it was saved as input into PyRx in the PDBQT file format.

\section{Molecular docking}

Molecular docking analysis is performed using the Autodock module available in PyRx Version 0.8 [18, 19]. The size of the docking grid is expanded to fit the entire protein within the grid with dimensions. Genetic Algorithm (GA) is used for screening the highest suitable blind docking conformers. During the docking period, the ligands are considered flexible and the protein as rigid. The configuration file for grid parameters is created by using the PyRx Auto Grid engine. The framework is used to know or predict the amino acids associated with the ligand at the active protein site. The maximum conformers have considered each compound to predict the best conformers in genetic algorithms through molecular docking. The best binding energy (most negative) is considered to note the ligand with maximum binding affinity. From each compound, the best conformer is selected for the interaction analysis. The selected docked complex of proteins and ligands were retrieved in PDB format and examined in PyMOL.

\section{The CAM vascular bed model}


Fertilized white leghorn chicken eggs weighing $50 \pm 2$ grams were incubated at $37^{\circ} \mathrm{C}$ in a humidified atmosphere (>60\% relative humidity) based on Hen's Egg Test- Chorioallantoic Membrane (HET-CAM) protocol. On the third day of post-incubation, 2 to $3 \mathrm{~mL}$ of albumin is withdrawn using a 21-gauge needle through the sizeable blunt edge of the eggs to minimize the adhesion of the shell membrane with the CAM. A square window of $1 \mathrm{~cm}^{2}$ in size is opened in the eggshell and was sealed with paraffin film to prevent dehydration. On day 9 , gelatinase sponges of $1 \mathrm{~mm}^{3}$ in size are placed on the top of the growing CAM under a sterile condition. The sponges are soaked with ten $\mu$ of 50,100 , and $150 \mu \mathrm{M}$ concentrations of Heparin. Control CAM is incubated with ten $\mu$ of $1 \mathrm{X}$ PBS. The window was closed with transparent adhesive tape, and the eggs are returned for further incubation till day 12 (72 hours of incubation), at which the vascularization potential of CAM reaches its maximum. The experiment groups are divided into 4 of, each containing 40 numbers of eggs. Group1 represents the control, groups 2, 3, and 4 correspond to $10 \mu \mathrm{L}$ volume of 50,100 , and $150 \mu \mathrm{M}$ concentrations of Heparin. CAMs were photographed at $0,24,48$, and 72 hours of incubation using a Cannon digital camera of $12 \times 50$ MegaPixel (Power Shot A95). The images are analyzed with Angioquant Toolbox, MATLAB 6.5 software to identify the blood vessels [4].

\section{Semi-Quantitative Reverse Transcriptase-Polymerase Chain Reaction (RT-PCR)}

According to the manufacturer protocol, total RNA is isolated from the tested CAMs (10 numbers each) using TRIzol reagent (100 mg/1 mL). The quantity and the purity of the isolated RNA are checked using a UV-visible spectrophotometer. Synthesize of cDNA of $20 \mu \mathrm{l}$ in volume was done using $\mathrm{ImProm}-11^{\mathrm{TM}}$ Reverse Transcriptase kit with Oligo (dt) of length 18-meres and random hexamers. PCR amplification is performed using a Go Taq Green Master Mix kit, and the changes in the level of mRNA expression of FGF2, MMP2, MMP9, NOS, VEGF A, VEGF C, and GAPDH are evaluated using 100 Pico moles of chicken specific primers. The relative expression level of each mRNA transcript is normalized with control. PCR products were subjected to electrophoresis on $1.5 \%$ agarose gel containing $0.5 \mu \mathrm{g} / \mathrm{ml} \mathrm{EtBr}$ and are photographed using a Canon Digital Camera of 12X5.0 MegaPixel resolution (Power Shot A95). The base pair products are compared against a DNA ladder of 10 base pairs. The relative density of the bands per experiment is calculated using a Scion Image release a 4.0 3.2 software. Specific primer sequences and the PCR reaction set up were given in Table 1 and 2, respectively [10].

\section{Gelatin zymography}

CAM tissues were homogenized $(100 \mathrm{mg} / \mathrm{mL})$ using Tris buffer $(0.5 \mathrm{M}$ Tris- $\mathrm{HCl}(\mathrm{pH}-6.8), 10 \%$ SDS, glycerol and $0.01 \%$ bromophenol blue) and centrifuged at $12,000 \mathrm{rpm} / 4^{\circ} \mathrm{C} / 10$ minutes. The protein concentration from the supernatant is determined using the Bradford reagent, and the gelatinase activity of the extracted samples is examined on a 10\% SDS-PAGE electrophoresis containing $1.0 \mathrm{mg} / \mathrm{mL}$ of gelatine. Protein samples of $25 \mu \mathrm{g} / 40 \mu \mathrm{L}$ in concentration and $20 \mu \mathrm{L}$ of pertained SDS-PAGE Standards marker are loaded in the system. After electrophoresis, the gels were washed with $2.5 \%$ of Triton-X-100 and incubated with the digestion buffer $(50 \mathrm{mM}$ Tris HCl-pH-7.5,100 mM CaCl2, $1 \mu \mathrm{M} \mathrm{ZnCl2,} 1$ \% Triton X$100,0.02 \%$ NaN3-100 mL) for 16 to 18 hours at $37^{\circ} \mathrm{C}$ with gentle agitation. Gels are stained with 
staining solution $(0.05 \%(\mathrm{w} / \mathrm{v}$, Coomassie blue in $50 \%$ methanol and $10 \%$ acetic acid) for 1 hour and destained with methanol/acetic acid mixture. The gels are scanned, and the images are recorded using a BIO-RAD Calibrated Densitometer Software (GS 800, USA). The bands' density is calculated with PD Quest Advances Software and normalized with control value [11].

\section{Immunohistochemistry}

CAM tissues incubated with ten $\mu \mathrm{L}$ of $100 \mu \mathrm{M}$ Heparin (10 $\mu \mathrm{M}$ in thickness) are deparaffinized and dehydrated and were allowed to undergo antigen retrieval process using Sodium Citrate (10 mM-pH 6.0) in a microwave oven for 20 minutes and washed with DDH2O for $3 X 5$ minutes in $1 X$ PBS (pH 7.3). Standard Goat Serum Blocking Solution ( $2 \%$ goat serum, $1 \%$ BSA, $0.1 \%$ cold fish skin gelatin, $0.1 \%$ Triton X-100, $0.05 \%$ Tween- 20, $0.05 \%$ Sodium Azide, 0.01 M PBS (pH 7.2) of 50 to $75 \mu \mathrm{L}$ in volume was added immediately on the sections and are incubated for 1 hour in a humidified chamber. After washing (IX PBS), the primary antibodies of FGF2, MMP2, and MMP9 were applied on the sections after diluted in a blocking serum. After overnight incubation, the sections are rinsed with 1 X PBS with $0.05 \%$ of Tween20. Diluted FITC (Goat anti-rabbit lgG) and HRP (both Goat anti-rabbit and Goat anti-mouse lgG) secondary antibodies (1:40 dilution) are applied for 1 hour according to the manufacturer's instruction. For HRP conjugated secondary antibodies DAB system was used for color development. The slides were finally counterstained with Mayer's hematoxylin and mounted with $90 \%$ of glycerol. For HRP conjugated system, the images are recorded using a light microscope. For FITC conjugation, the images are taken using BX51 Olympus Fluorescence Microscope at a wavelength of $515 \mathrm{~nm}$ with ASI FISH View 5.5 software at 40X magnification [10].

\section{Scanning electron microscopic (SEM) analysis}

The tested area of the CAM (with $100 \mu \mathrm{M}$ Heparin) is dissected after 72 hours of incubation and washed with 1X PBS. After drying at room temperature, the unfolded air-dried membranes are glued onto stubs with carbon spattered with gold (10 min, 14-17 Ma, and $0.07 \mathrm{~m}$ bar). The sections are observed under a Hitachi S-3400N Variable Pressure Scanning Electron Microscope (Hitachi, Tokyo, Japan) at an accelerating voltage of $15-30 \mathrm{kV}$, and the images are recorded at $100 \mathrm{X}$ magnification [20].

\section{Data analysis and statistics}

All the experiments were performed in triplicate $(n=3)$ unless otherwise specified. Data are presented as mean \pm SEM and are analyzed by One-Way ANOVA analysis of variance test, Student's t-test, and Turkey post hoc tests as appropriate by Sigma Stat 2.0. Values of $p=<0.001$ and $p=0.001$ were considered as statistically significant.

\section{Declarations}

\section{Ethics approval and consent to participate}

Not applicable 


\section{Consent for publication}

Not applicable

\section{Availability of data and materials}

All the data generated or analyzed during this study are included in this published article.

\section{Competing interests}

No competing interest

\section{Funding}

No funds, grants, or other support are received for conducting this study.

\section{Author's contribution}

RM design the work, carried out the experimental studies and made the manuscript. VP performed the molecular docking analysis. MR reviewed the manuscript. All the authors have read and approved the manuscript.

\section{Acknowledgment}

We want to thank Dr. Li Haiqing, MD, Ph.D., -Technology transfer specialist, National Cancer Institute, Rockville, USA, for the kind gift of Rabbit polyclonal MMP2 and FGF2 antibodies.

\section{Abbreviations}

HMWH- High molecular weight heparin

CAM-Chorioallantoic Membrane

VEGF-Vascular Endothelial Growth Factor

MMP- Matrix Metalloproteinase

PCR-Polymerase Chain Reaction

EC - Endothelial Cell

ECM - Extra Cellular Matrix

NOS3 - Endothelial Nitric Oxide Synthase

NO- Nitric Oxide 


\section{References}

1. Yoo SY, Kwon SM. Angiogenesis and its therapeutic opportunities. Mediators Inflamm. 2013;2013:127170. DOI:10.1155/2013/127170. PMID: 23983401; PMCID: PMC3745966.

2. Burgess WH, Maciag T. The heparin-binding (fibroblast) growth factor family of proteins. Annu Rev Biochem. 1989; 58:575-606. DOI: 10.1146/annurev.bi.58.070189.003043. PMID: 2549857.

3. Hoeben A, Landuyt B, Highley MS, Wildiers H, Van Oosterom AT, De Bruijn EA. Vascular endothelial growth factor and angiogenesis. Pharmacol Rev. 2004 Dec; 56(4):549 - 80. DOI: 10.1124/pr.56.4.3. PMID: 15602010.

4. Rema RB, Rajendran K, Ragunathan M. Angiogenic efficacy of Heparin on chick chorioallantoic membrane. Vasc Cell. 2012 Apr 18;4(1):8. DOI: 10.1186/2045-824X-4-8. PMID: 22513007; PMCID: PMC3514200.

5. Gray E, Mulloy B, Barrowcliffe TW. Heparin and low-molecular-weight Heparin. Thromb Haemost. 2008 May; 99(5):807 - 18. DOI: 10.1160/TH08-01-0032. PMID: 18449410.

6. Tiozzo R, Cingi MR, Croce MA. Interaction of heparan sulfate and its fractions with endothelial cells in culture. Int J Tissue React. 1993; 15(4):163-8. PMID: 8188456.

7. Nissen NN, Shankar R, Gamelli RL, Singh A, DiPietro LA. Heparin and heparan sulphate protect basic fibroblast growth factor from non-enzymic glycosylation. Biochem J. 1999 Mar 15; 338 (Pt 3)(Pt 3):637 - 42. PMID: 10051433; PMCID: PMC1220097.

8. Rak J, Weitz JI. Heparin and angiogenesis: size matters! Arterioscler Thromb Vasc Biol. 2003 Nov 1; 23(11):1954-5. DOI: 10.1161/01.ATV.0000100563.16983.19. PMID: 14617616.

9. Nowak-Sliwinska P, Segura T, Iruela-Arispe ML. The chicken chorioallantoic membrane model in biology, medicine and bioengineering. Angiogenesis. 2014 Oct;17(4):779-804. DOI:10.1007/s10456014-9440-7. Epub 2014 Aug 20. PMID: 25138280; PMCID: PMC4583126.

10. Manjunathan R, Ragunathan M. In ovo administration of human recombinant leptin shows dosedependent angiogenic effect on chicken chorioallantoic membrane. Biol Res. 2015 Jun 10;48(1):29. DOI: 10.1186/s40659-015-0021-z. PMID: 26060038; PMCID: PMC4470073.

11. Manjunathan R, Ragunathan M. Evaluation of Antiangiogenic Potential of MMP2 Antisense Oligonucleotide for the Management of Proliferative Diabetic Retinopathy Using Chicken Chorioallantoic Membrane. Mol Biol. 2016;5:148.

12. UniProt Consortium. UniProt: a worldwide hub of protein knowledge. Nucleic Acids Res. 2019 Jan 8;47(D1):D506-D515. DOI: 10.1093/nar/gky1049. PMID: 30395287; PMCID: PMC6323992.

13. Waterhouse A, Bertoni M, Bienert S, Studer G, Tauriello G, Gumienny R, Heer FT, de Beer TAP, Rempfer C, Bordoli L, Lepore R, Schwede T. SWISS-MODEL: homology modelling of protein structures and complexes. Nucleic Acids Res. 2018 Jul 2;46(W1):W296-W303. DOI: 10.1093/nar/gky427. PMID: 29788355; PMCID: PMC6030848.

14. Cardoso JMS, Fonseca L, Egas C, Abrantes I. Cysteine proteases secreted by the pinewood nematode, Bursaphelenchus xylophilus: In silico analysis. Comput Biol Chem. 2018 Dec;77:291-296. 
DOI: 10.1016/j.compbiolchem.2018.10.011. Epub 2018 Oct 26. PMID: 30399505.

15. Benkert P, Künzli M, Schwede T. QMEAN server for protein model quality estimation. Nucleic Acids Res. 2009 Jul;37(Web Server issue):W510-4. DOI: 10.1093/nar/gkp322. Epub 2009 May 8. PMID: 19429685; PMCID: PMC2703985.

16. Laskowski RA, MacArthur MW, Moss DS, Thornton JM. PROCHECK: a program to check the stereochemical quality of protein structures. J Appl Crystal. 1993;26:283-91.

17. Trott O, Olson AJ. AutoDock Vina: improving the speed and accuracy of docking with a new scoring function, efficient optimization, and multithreading. J Comput Chem. 2010 Jan 30;31(2):455 - 61. DOI: 10.1002/jcc.21334. PMID: 19499576; PMCID: PMC3041641.

18. Morris GM, Huey R, Lindstrom W, Sanner MF, Belew RK, Goodsell DS, Olson AJ. AutoDock4 and AutoDockTools4: Automated docking with selective receptor flexibility. J Comput Chem. 2009 Dec;30(16):2785-91. DOI:10.1002/jcc.21256. PMID: 19399780; PMCID: PMC2760638.

19. Lill MA, Danielson ML. Computer-aided drug design platform using PyMOL. J Comput Aided Mol Des. 2011 Jan;25(1):13 - 9. DOI: 10.1007/s10822-010-9395-8. Epub 2010 Oct 30. PMID: 21053052.

20. Manjunathan R, Ragunathan M. Chicken chorioallantoic membrane as a reliable model to evaluate osteosarcoma-an experimental approach using SaOS2 cell line. Biol Proced Online. 2015 Jun 6;17:10. DOI: 10.1186/s12575-015-0022-x. PMID: 26109911; PMCID: PMC4479062.

21. Presta M, Leali D, Stabile H, Ronca R, Camozzi M, Coco L, Moroni E, Liekens S, Rusnati M. Heparin derivatives as angiogenesis inhibitors. Curr Pharm Des. 2003;9(7):553 - 66. DOI: 10.2174/1381612033391379. PMID: 12570803.

22. Svahn $\mathrm{CM}$, Weber M, Mattsson C, Neiger K, Palm M. Inhibition of angiogenesis by heparin fragments in the presence of hydrocortisone. Carbohyd Polym. 1992;18(1):9-16. https://doi.org/10.1016/01448617(92)90182-P. ISSN 0144-8617.

23. Chiarelli P, Mitola S, Ravelli C, Oreste P, Rusnati M, Presta M. Heparan sulfate proteoglycans mediate the angiogenic activity of the vascular endothelial growth factor receptor-2 agonist gremlin. Arterioscler Thromb Vasc Biol. 2011 Dec;31(12):e116-27. DOI:10.1161/ATVBAHA.111.235184. Epub 2011 Sep 15. PMID: 21921258.

24. Padera R, Venkataraman G, Berry D, Godavari R, Sasisekharan R. FGF-2/fibroblast growth factor receptor/heparin-like glycosaminoglycan interactions: a compensation model for FGF-2 signaling. FASEB J. 1999 Oct;13(13):1677-87. DOI: 10.1096/fasebj.13.13.1677. PMID: 10506571.

25. López-Casillas F, Cheifetz S, Doody J, Andres JL, Lane WS, Massagué J. Structure and expression of the membrane proteoglycan betaglycan, a component of the TGF-beta receptor system. Cell. 1991 Nov 15;67(4):785 - 95. DOI: 10.1016/0092-8674(91)90073-8. PMID: 1657406.

26. Kanwar YS, Farquhar MG. Presence of heparan sulfate in the glomerular basement membrane. Proc Natl Acad Sci U S A. 1979 Mar;76(3):1303-7. DOI:10.1073/pnas.76.3.1303. PMID: 155819; PMCID: PMC383239.

27. Williams MP, Streeter HB, Wusteman FS, Cryer A. Heparan sulphate and the binding of lipoprotein lipase to porcine thoracic aorta endothelium. Biochim Biophys Acta. 1983 Mar 15;756(1):83-91. DOI: 
10.1016/0304-4165(83)90027-2. PMID: 6218833.

28. Litwin M, Radwańska A, Paprocka M, Kieda C, Dobosz T, Witkiewicz W, Baczyńska D. The role of FGF2 in migration and tubulogenesis of endothelial progenitor cells in relation to pro-angiogenic growth factor production. Mol Cell Biochem. 2015 Dec;410(1-2):131-42. doi: 10.1007/s11010-0152545-5. Epub 2015 Aug 28. PMID: 26314253.

29. Huber R, Attili/Abedalkhader R, Küper D, Hauke L, Lüns B, Brand K, Weissenborn K, Lichtinghagen R. Cellular and Molecular Effects of High-Molecular-Weight Heparin on Matrix Metalloproteinase 9 Expression. Int J Mol Sci. 2019 Mar 30;20(7):1595. DOI: 10.3390/ijms20071595. PMID: 30935029; PMCID: PMC6479594.

30. Mannello F, Jung K, Tonti GA, Canestrari F. Heparin affects matrix metalloproteinases and tissue inhibitors of metalloproteinases circulating in peripheral blood. Clin Biochem. 2008 Dec;41(18):1466-73. DOI: 10.1016/j.clinbiochem.2008.09.104. Epub 2008 Oct 2. PMID: 18926810.

31. Lackey B, Nunes QM, Higham SM, Fernig DG, Valappil SP. In silico analyses of heparin-binding proteins expression in human periodontal tissues. BMC Res Notes. 2016 Jan 28;9:53. DOI: 10.1186/s13104-016-1857-1. PMID: 26821679; PMCID: PMC4731997.

32. Saleh A, Stathopoulou MG, Dadé S, Ndiaye NC, Azimi-Nezhad M, Murray H, Masson C, Lamont J, Fitzgerald P, Visvikis-Siest S. Angiogenesis related genes NOS3, CD14, MMP3 and IL4R are associated to VEGF gene expression and circulating levels in healthy adults. BMC Med Genet. 2015 Oct 5;16:90. DOI: 10.1186/s12881-015-0234-6. PMID: 26437765; PMCID: PMC4594922.

33. Li Y, Talotta-Altenburg LM, Silimperi KA, Ciabattoni GO, Lowe-Krentz LJ. Endothelial nitric oxide synthase activation is required for heparin receptor effects on vascular smooth muscle cells. Am J Physiol Cell Physiol. 2020 Mar 1;318(3):C463-C475. DOI: 10.1152/ajpcell.00284.2018. Epub 2019 Dec 31. PMID: 31891520; PMCID: PMC7099515.

34. Kouretas PC, Kim YD, Cahill PA, Myers AK, To LN, Wang YN, Wallace RB, Kron IL, Hannan RL. Heparin preserves nitric oxide activity in coronary endothelium during ischemia-reperfusion injury. Ann Thorac Surg. 1998 Oct;66(4):1210-5. DOI: 10.1016/s0003-4975(98)00811-x. PMID: 9800808.

35. Upchurch GR Jr, Welch GN, Freedman JE, Fabian AJ, Pigazzi A, Scribner AM, Alpert CS, Keaney JF Jr, Loscalzo J. High-dose heparin decreases nitric oxide production by cultured bovine endothelial cells. Circulation. 1997 Apr 15;95(8):2115-21. DOI: 10.1161/01.cir.95.8.2115. PMID: 9133522.

36. Zhang M, Liu Y, Cui F, Rankl C, Qin J, Guan Y, Guo X, Zhang B, Tang J. Interaction of vascular endothelial growth factor and Heparin quantified by single-molecule force spectroscopy. Nanoscale. 2020 Jun 11;12(22):11927-11935. DOI: 10.1039/d0nr01570a. PMID: 32458960.

37. Tessler S, Rockwell P, Hicklin D, Cohen T, Levi BZ, Witte L, Lemischka IR, Neufeld G. Heparin modulates the interaction of VEGF165 with soluble and cell-associated flk-1 receptors. J Biol Chem. 1994 Apr 29;269(17):12456-61. PMID: 8175651.

38. Ono K, Hattori H, Takeshita S, Kurita A, Ishihara M. Structural features in Heparin that interact with VEGF165 and modulate its biological activity. Glycobiology. 1999 Jul;9(7):705 - 11. DOI: 10.1093/glycob/9.7.705. PMID: 10362840. 


\section{Tables}

Table 1

Primers sequences

\begin{tabular}{|c|c|c|}
\hline Gene & Primer Sequence & Base Pair \\
\hline \multirow[t]{2}{*}{ FGF2 } & Sense- 5'-TTCTTCCTGCGCATCAAC-3' & $250 \mathrm{bp}$ \\
\hline & Antisense-5'-GGATAGCTTTCTGTCCAG-3' & \\
\hline \multirow[t]{2}{*}{ MMP2 } & Sense- 5'-CCTACACCAAGAACTTCC-3' & $580 \mathrm{bp}$ \\
\hline & Antisense-5'-ACTCCATTCCAAGAATCC-3' ( & \\
\hline \multirow[t]{2}{*}{ MMP9 } & Sense-5'-GATGCYCAYTTYGATGATGATGAG-3' & $1400 \mathrm{bp}$ \\
\hline & Antisense-5'-GGTCCARTATTTYCCRTYCTTGA-3' & \\
\hline \multirow[t]{2}{*}{ NOS3 } & Sense- 5'-CCAGAGAGATTCATCTGACCG-3' & $530 \mathrm{bp}$ \\
\hline & Antisense- 5'-GGTCCCTACAACGAGTCTGAA-3' & \\
\hline \multirow[t]{2}{*}{ VEGF $(165 / 190)$} & Sense-5'-GACCCTGGTGGACATTTTCC-3' & VEGF165 -381 bp \\
\hline & Antisense-5'-TGCGCTCGTTTAACTCAAGC-3' & VEGF190- 456 bp \\
\hline \multirow[t]{2}{*}{ GAPDH } & Sense- 5'- GAGGAAAGGTCGCCTGGTGGATCG-3' & $300 \mathrm{bp}$ \\
\hline & Antisense-5'-GTGAGGACAAGCAGTGAGGAACG-3' & \\
\hline
\end{tabular}

\section{Table 2}

The amplification conditions are as follows,

\begin{tabular}{|lllll|}
\hline Gene Name & Denaturation & Annealing & Extension & Cycles \\
\hline FGF2 & $94^{\circ} \mathrm{C} / 1 \mathrm{~min}$ & $54^{\circ} \mathrm{C} / 1 \mathrm{~min}$ & $72^{\circ} \mathrm{C} / 1 \mathrm{~min}$ & 35 \\
\hline MMP2 & $94^{\circ} \mathrm{C} / 30 \mathrm{sec}$ & $60^{\circ} \mathrm{C} / 30 \mathrm{sec}$ & $72^{\circ} \mathrm{C} / 1 \mathrm{~min}$ & 35 \\
\hline MMP9 & $94^{\circ} \mathrm{C} / 30 \mathrm{sec}$ & $48^{\circ} \mathrm{C} / 30 \mathrm{sec}$ & $72^{\circ} \mathrm{C} / 1 \mathrm{~min}$ & 35 \\
\hline NOS3 & $94^{\circ} \mathrm{C} / 1 \mathrm{~min}$ & $57^{\circ} \mathrm{C} / 40 \mathrm{sec}$ & $68^{\circ} \mathrm{C} / 1.5 \mathrm{~min}$ & 30 \\
\hline VEGF $(165 / 190)$ & $94^{\circ} \mathrm{C} / 1 \mathrm{~min}$ & $59^{\circ} \mathrm{C} / 1 \mathrm{~min}$ & $72^{\circ} \mathrm{C} / 1 \mathrm{~min}$ & 40 \\
\hline GAPDH & $94^{\circ} \mathrm{C} / 30 \mathrm{sec}$ & $60^{\circ} \mathrm{C} / 30 \mathrm{sec}$ & $72^{\circ} \mathrm{C} / 1 \mathrm{~min}$ & 35 \\
\hline
\end{tabular}




\section{Table 3}

Bonding energy and hydrogen bond details if chicken-specific pro-angiogenic growth factors with heparin sulphate 


\begin{tabular}{|c|c|c|c|}
\hline & & Binding Energy kcal/mol & \\
\hline No & Protein name & & Hydrogen bond details \\
\hline \multirow{6}{*}{1} & & & LYS-33 \\
\hline & FGF2 & -12.5 & GLN-66 \\
\hline & & & LEU-67 \\
\hline & & & ALA-69 \\
\hline & & & LEU-110 \\
\hline & & & ASN-116 \\
\hline \multirow{6}{*}{2} & & & GLU-214 \\
\hline & MMP2 & -10.4 & PHE-232 \\
\hline & & & ASO-389 \\
\hline & & & GLN-390 \\
\hline & & & ASP-518 \\
\hline & & & LEU-551 \\
\hline \multirow{9}{*}{3} & & & LYS-186 \\
\hline & MMP9 & -10.1 & ASP-187 \\
\hline & & & LYS-371 \\
\hline & & & ASP-391 \\
\hline & & & ARG-392 \\
\hline & & & TYR-394 \\
\hline & & & TYR-424 \\
\hline & & & SER-425 \\
\hline & & & PRO-545 \\
\hline \multirow{7}{*}{4} & & & THR-40 \\
\hline & NOS3 & -9.1 & VAL-130 \\
\hline & & & ASN-132 \\
\hline & & & ASN-148 \\
\hline & & & GLU-155 \\
\hline & & & ARG-166 \\
\hline & & & GLU-56 \\
\hline
\end{tabular}




\begin{tabular}{|c|c|c|c|}
\hline \multirow[t]{6}{*}{5} & VGEF A & -8.6 & LEU-58 \\
\hline & & & CYS-83 \\
\hline & & & GLY-85 \\
\hline & & & LEU-92 \\
\hline & & & GLU-93 \\
\hline & & & CYS-94 \\
\hline \multirow{5}{*}{6} & & & ARG-301 \\
\hline & VGEF C & -8.2 & CYS-304 \\
\hline & & & ASP-306 \\
\hline & & & GLY-331 \\
\hline & & & CYS-340 \\
\hline
\end{tabular}

Figures 

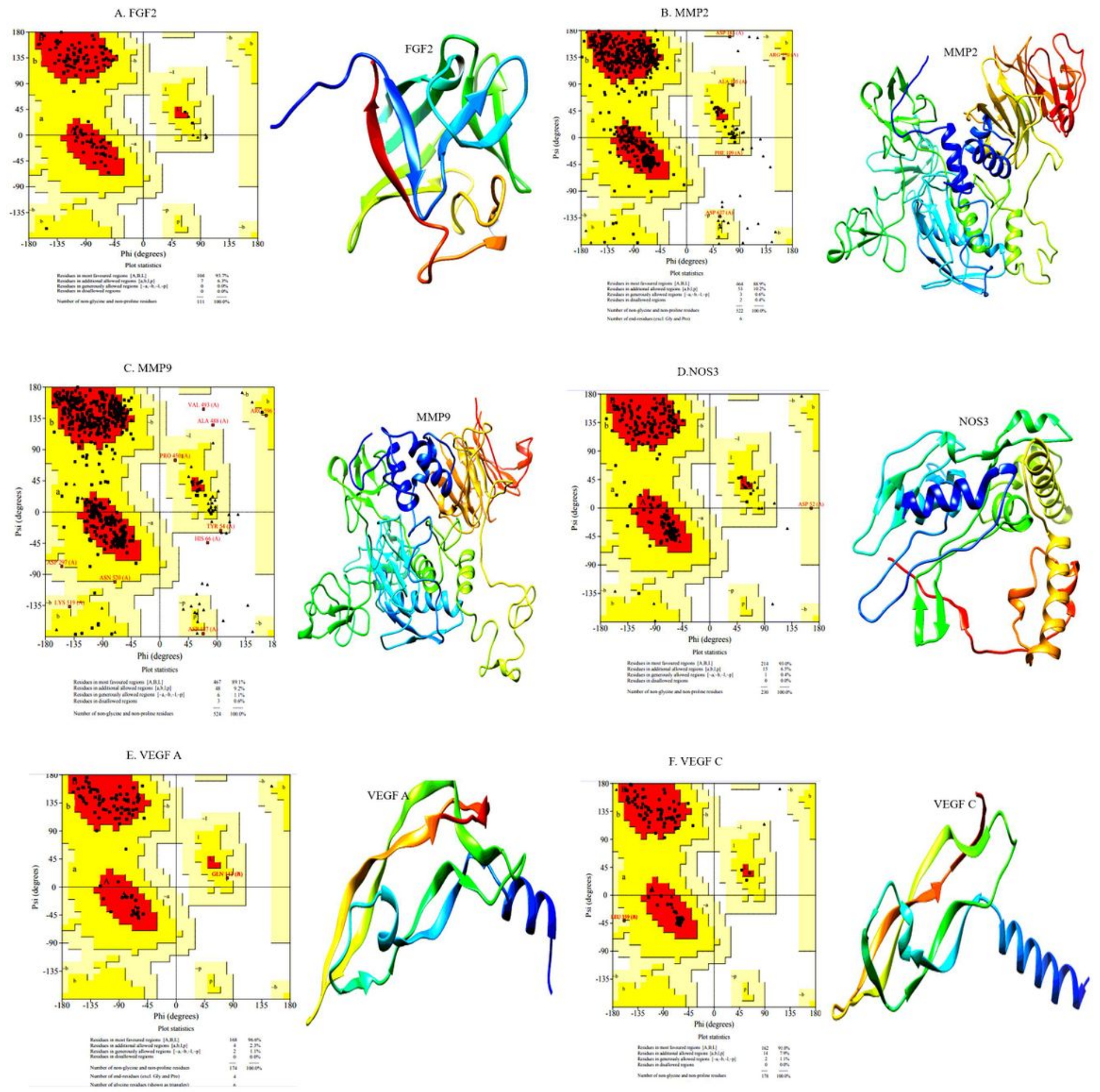

Figure 1

Ramachandran Plots and $3 \mathrm{D}$ structures of chicken-specific angiogenic growth factors. $3 \mathrm{D}$ structural validation of chicken-specific pro-angiogenic growth factors. A)FGF2, B) MMP2, C) MMP9, D) NOS3, E) VEGF A, and F) VEGF C. The structure is validated with the SWISS-MODEL web server. 
A. FGF2

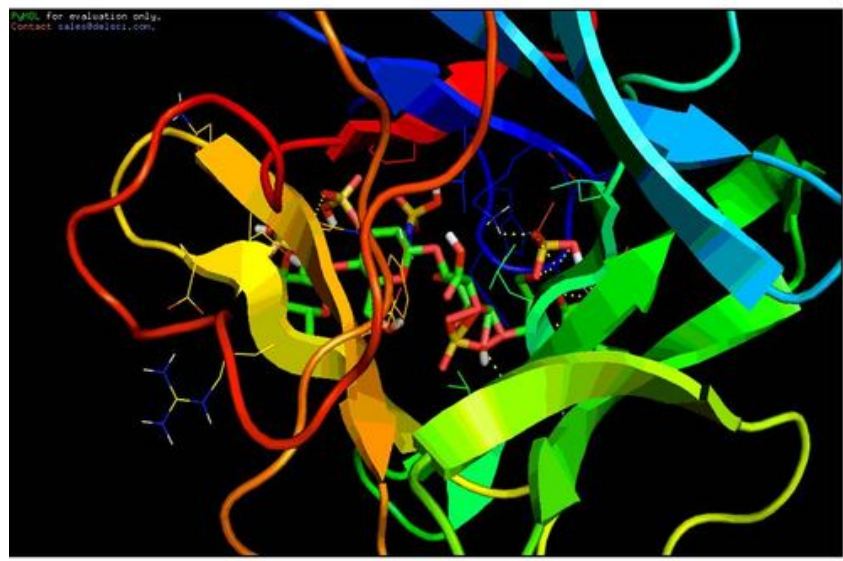

C. MMP9

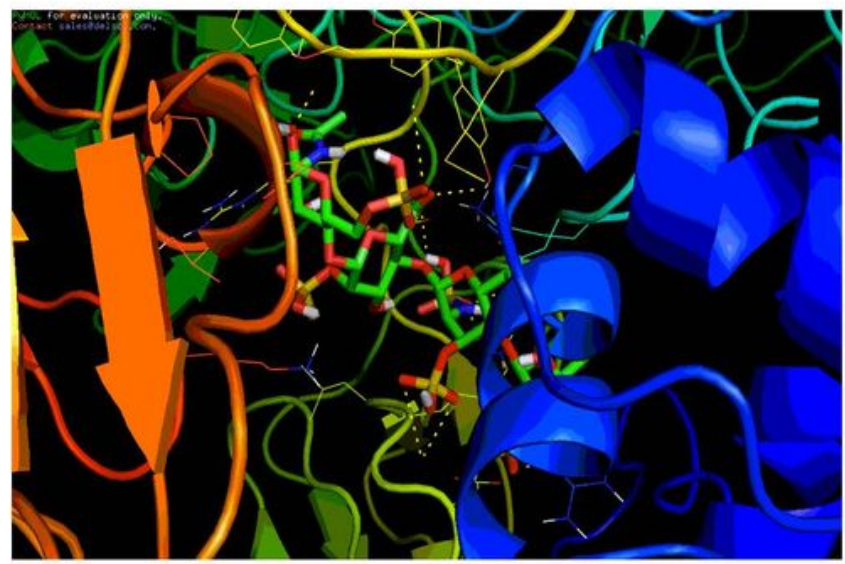

E. VEGF A

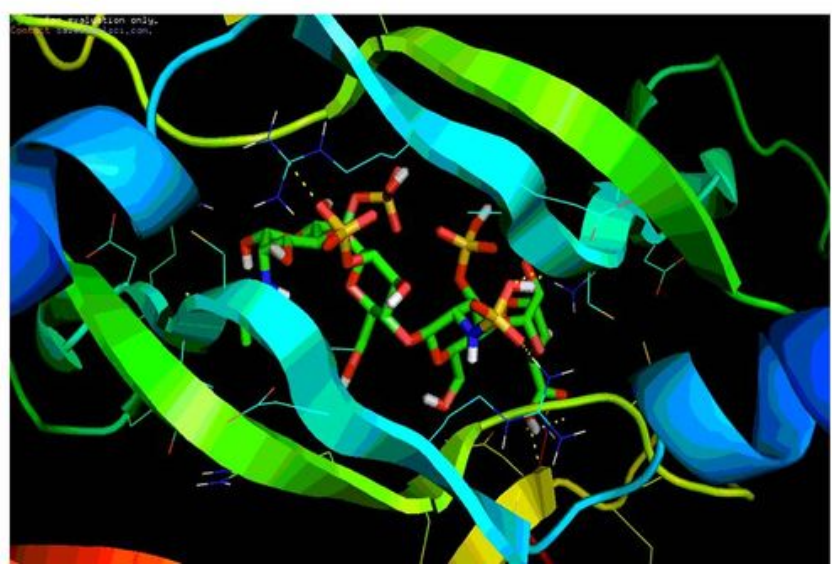

B. MMP2

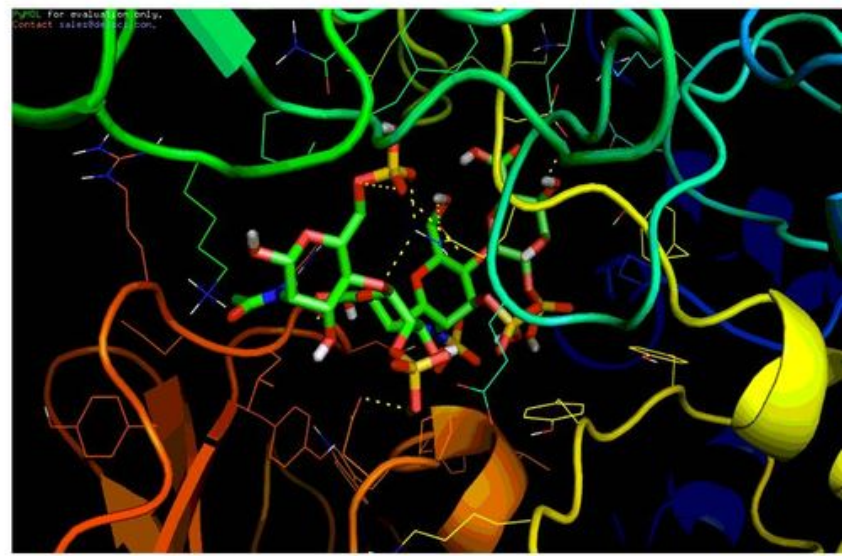

D. NOS3

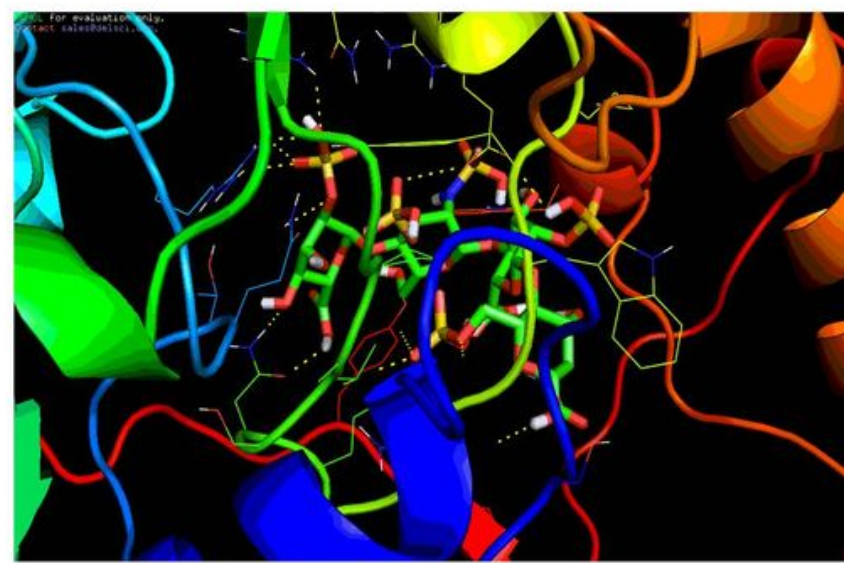

F. VEGF B

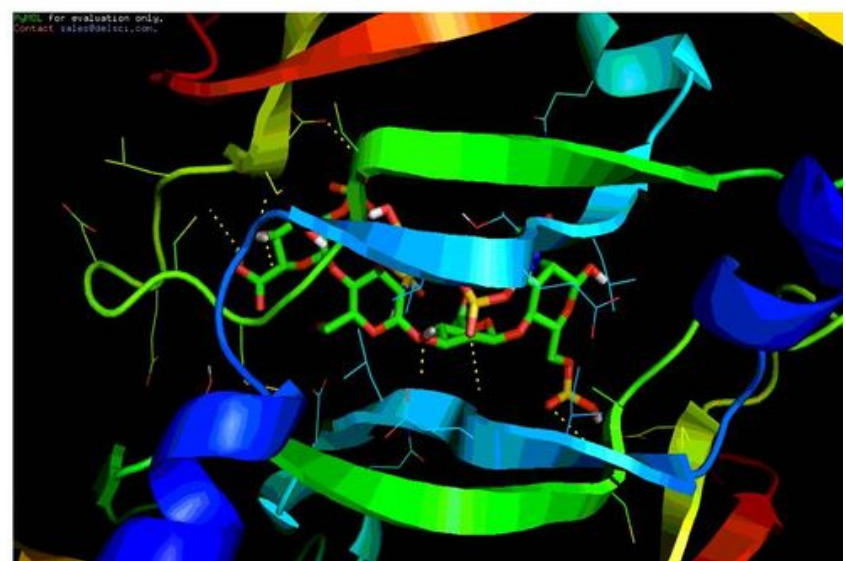

\section{Figure 2}

Molecular docking analysis- The image represents the binding pattern of chicken-specific pro-angiogenic growth factors with Heparin. The analysis is performed using the Autodock module available in PyRx Version 0.8. (A) Heparin with FGF2 - binding energy is $-12.5 \mathrm{Kcal} / \mathrm{mol} /$ with 6 hydrogen bonds, (B) Heparin with MMP2 - binding energy is $-10.4 \mathrm{Kcal} / \mathrm{mol}$ with 6 hydrogen bonds, (C) Heparin with MMP9- binding energy is $-10.1 \mathrm{Kcal} / \mathrm{mol}$ with 9 hydrogen bonds, (D) Heparin with NOS3 - binding energy is $-9.3 \mathrm{Kcal} / \mathrm{mol}$ 
with 6 hydrogen bonds, (E) Heparin with VEGF A - binding energy is -8.6 with $\mathrm{Kcal} / \mathrm{mol}$ with 7 hydrogen bonds, (F) Heparin with VEGF C- binding energy is $-8.2 \mathrm{Kcal} / \mathrm{mol}$ with 5 hydrogen bonds. Among the analyzed combinations, Heparin shows the most significant binding affinity with the FGF2 molecule.

Figure 3. HMWH induces angiogenesis on CAM vascular bed

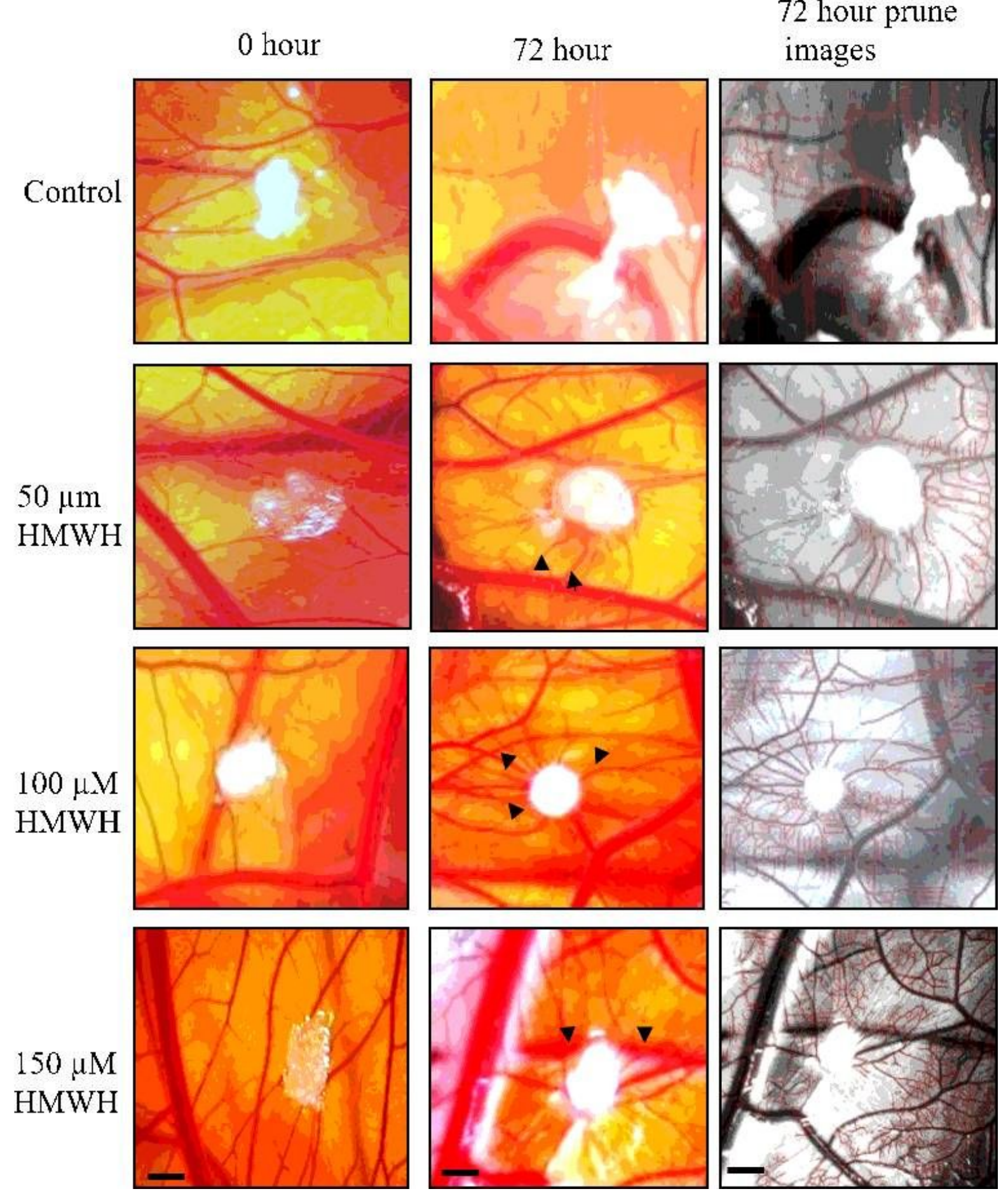

Figure 3

HMWH induces angiogenesis on CAM vascular bed. Images of CAM vascular bed incubated with 50,100 , and $150 \mu \mathrm{M}$ concentration of HMWH for 72 hours. Control CAM is incubated with 1X PBS. CAM 
incubated with $100 \mu \mathrm{M}$ concentration of Heparin shows dense vascularization around the sponge (black arrow) as a spoke wheel pattern, which is comparatively higher than the effect of other concentrations. The observation is supported by skeletonized prune images by Angioquant software in which the blood vessels are marked as red lines. Images are taken using Canon digital camera at $4 \mathrm{X}$ magnification.

Figure 4- HMWH up-regulates the molecular level expression of chicken-specific pro-angiogenic growth factors
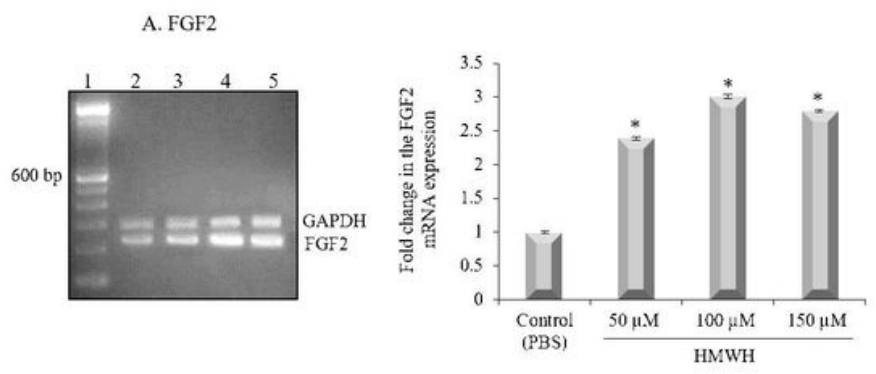

C. MMP9
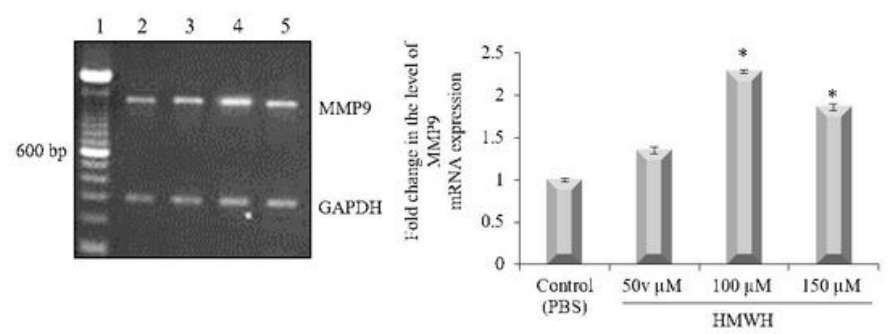

E. VEGF A and VEGF C

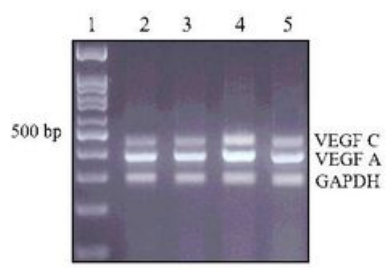

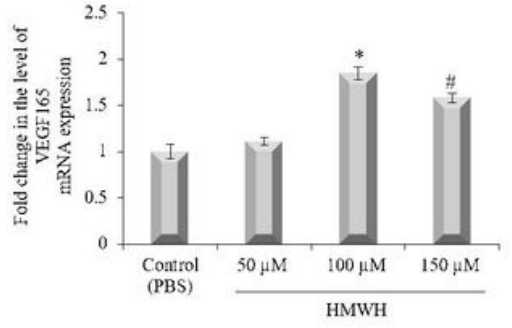
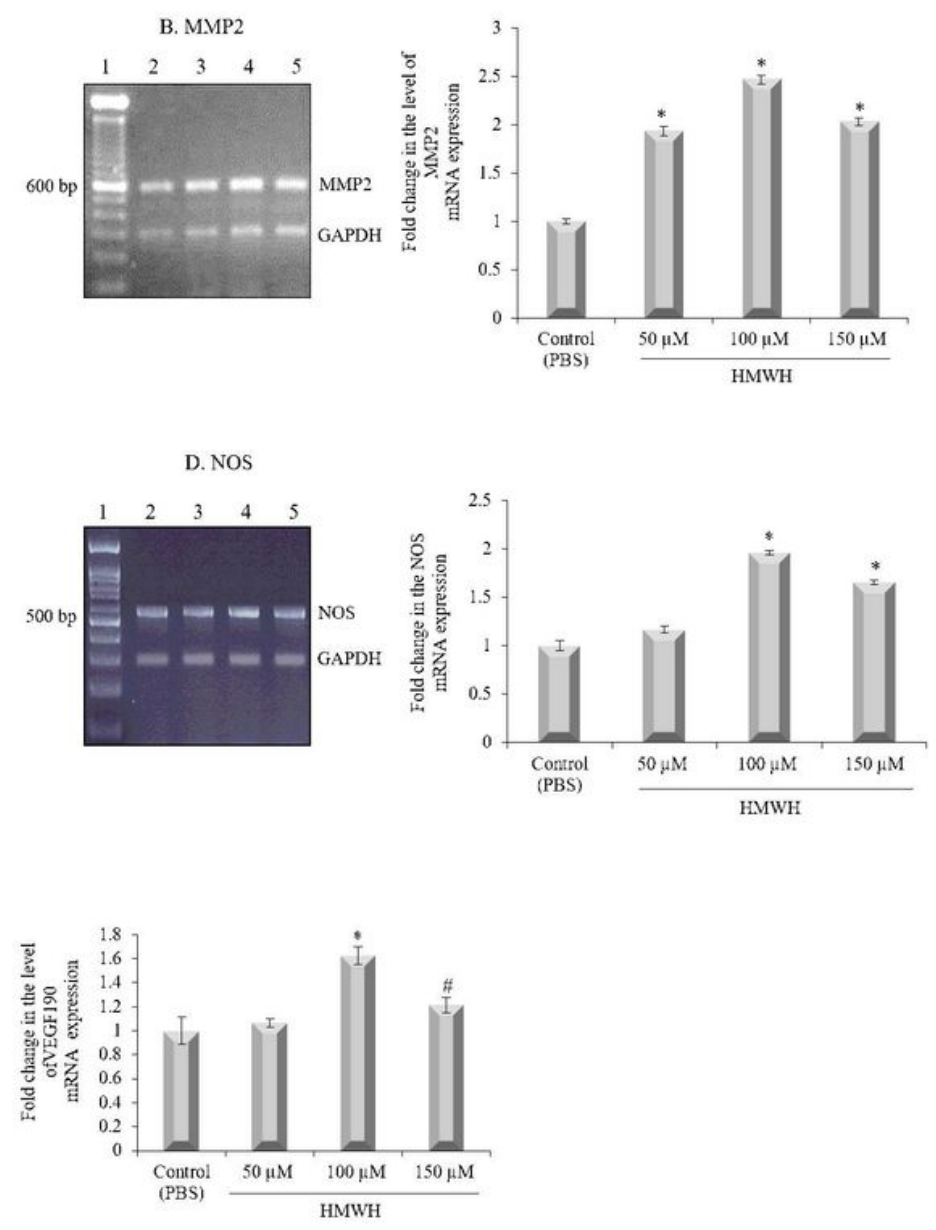

\section{Figure 4}

HMWH up-regulates the molecular level expression of chicken-specific pro-angiogenic growth factors. Images of Reverse Transcriptase - PCR products of (A) FGF2, (B) MMP2, (C) MMP9, (D) NOS3, (E) VEGF $A$, and $(F)$ VEGF $C$ from CAM after the incubation with 50, 100, and $150 \mu \mathrm{M}$ concentrations of HMWH for 72 hours. Control CAM is incubated with $1 \mathrm{X}$ PBS. GAPDH is used as an internal loading control. The transcripts are confirmed by $100 \mathrm{bp}$ DNA ladder. Graphs represent the OD value ratio of mRNA transcripts after normalizing with GADPH OD value of the same. The OD value is measured using Image $\mathrm{J}$ software. The relative level expression of specified genes are increased significantly under all concentrations of HMWH. The relative expression of FGF2 and MMP2 increased significantly under all concentrations of $H M W H$. Each value is the mean $\pm S E M,{ }^{*} p=<0.001$ and $\# P=0.001$. Experiments are performed in triplicate, and the data presented as mean + SEM. (Lane 1 - marker, lane 2- control, lane $3-50 \mu \mathrm{M}$ $\mathrm{HMWH}$, lane 4 - $100 \mu \mathrm{M} \mathrm{HMWH}$, and lane 5- $150 \mu \mathrm{M} \mathrm{HMWH).}$ 
Figure 5- HMWH accelerates MMP2 mediated basement membrane degradation

\section{Figure 5. A}

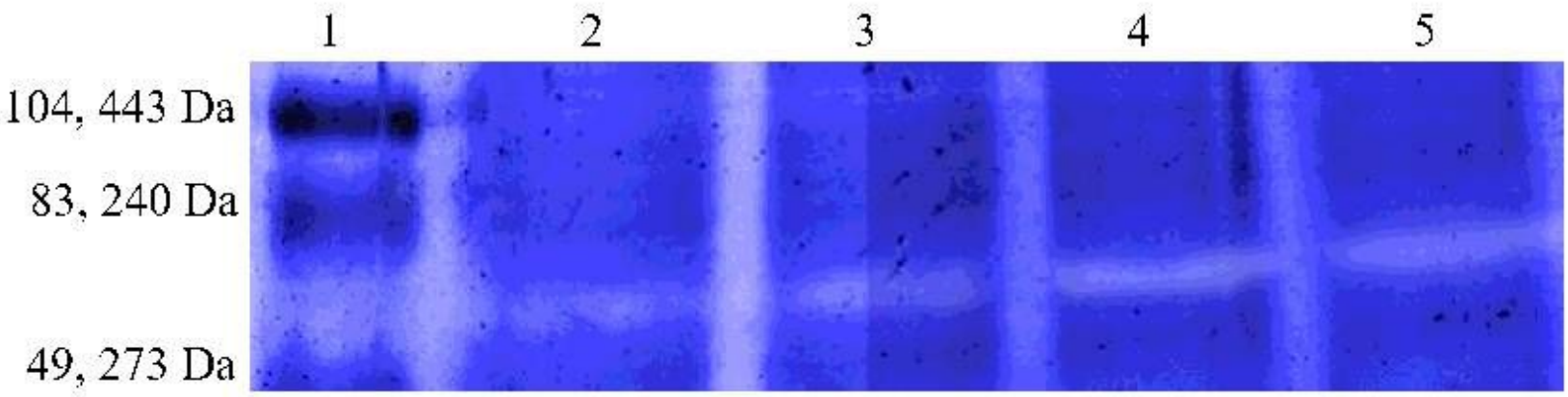

Figure 5. B

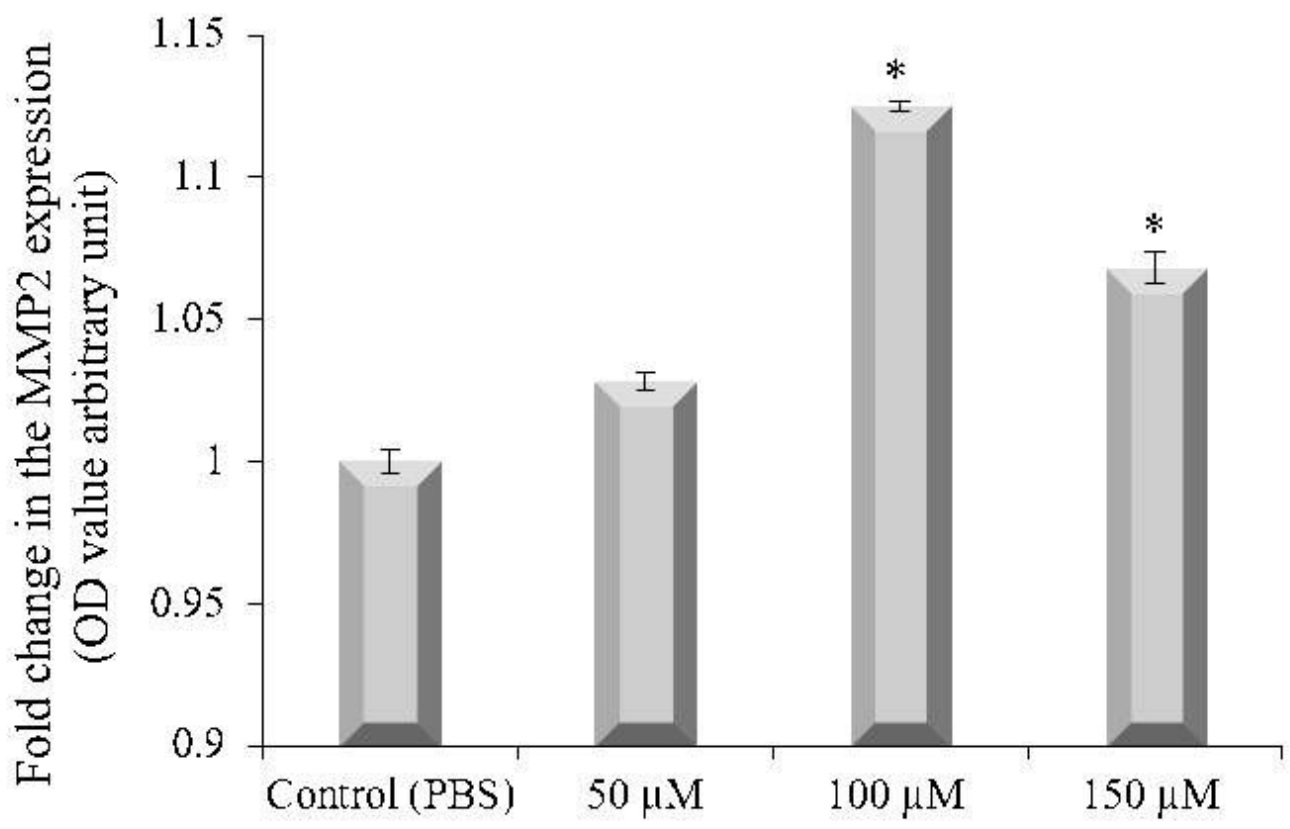

\section{Figure 5}

HMWH accelerates MMP2 mediated basement membrane degradation. Figure 5. A. represents the gel image of gelatine zymography of MMP2 activity after the incubation with 50, 100, and 150 concentrations of HMWH for 72 hours. Control CAM is incubated with 1X PBS. The image shows that the gelatinase activity is increased under 100 and $150 \mu \mathrm{M}$ concentrations of $\mathrm{HMWH}$ which is visible as a white band against the blue background and with a higher effect under $100 \mu \mathrm{M}$ concentration. Figure 5.B. Graphical representation of gelatinase activity of MMP2 under HMWH incubation in terms of OD value. The OD value is measured using Image $\mathrm{J}$ software. The gelatinase activity of MMP2 enhanced 
significantly under 100 and $150 \mu \mathrm{M}$ concentration of $\mathrm{HMWH}$, with comparatively higher impact under 100 $\mu \mathrm{M}$ concentration. Experiments are performed in triplicate, and the data are presented as mean + SEM, and ${ }^{*} \mathrm{p}=<0.001$ versus control. (Lane 1- protein marker, lane 2- control, lane $3-50 \mu \mathrm{M} \mathrm{HMWH}$, lane $4-$ $100 \mu \mathrm{M} H \mathrm{HWH}$, and lane 5- $150 \mu \mathrm{M} \mathrm{HMWH})$.

\section{Figure 6- HMWH up-regulates the protein level expression of FFG2 and MMP2}

\section{Control (PBS)}

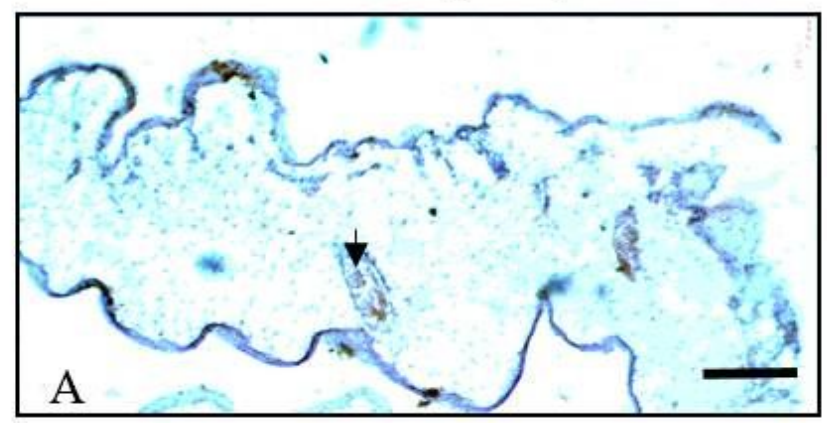

FGF2

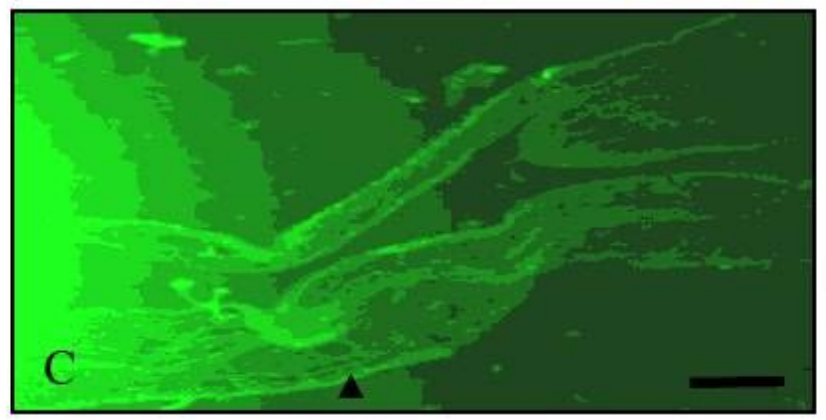

CAM incubated with $100 \mu \mathrm{M}$ HMWH
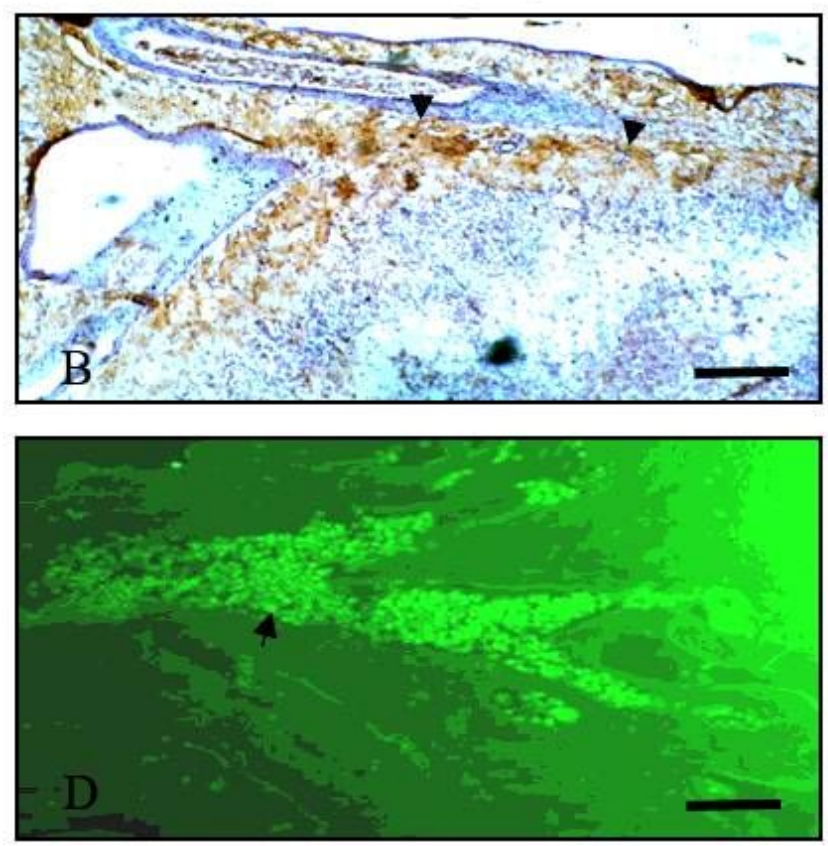

\section{Figure 6}

HMWH up-regulates the protein level expression of FGF2 and MMP2. Immunohistochemical images of CAM with FGF2 and MMP2 expression after the incubation with $100 \mu \mathrm{M}$ concentration of HMWH for 72 hours. Control CAM is incubated with 1X PBS. Control CAM shows the presence of FGF2 in ECs trapped at the small vessels (Figure 6.A) and a substantial presence of MMP2 throughout the chorionic layer (Figure 6.C). CAM incubated with $100 \mu \mathrm{M}$ concentration of HMWH shows the presence of FGF2 in the chorionic layer, majorly at the stromal region and also by ECs trapped at large and small vessels (Figure 6.B). CAM incubated with $100 \mu \mathrm{M}$ concentration of HMWH shows the presence of more MMP2 expression throughout the chorionic layer and in sub-epithelial capillary network region than the control (Figure 6.D). Images are recorded by light and BX51 Olympus fluorescence microscopes. Arrow indicates the presence of protein, magnification is $60 \mathrm{X}$, and the magnification bar is 50 micrometer. 

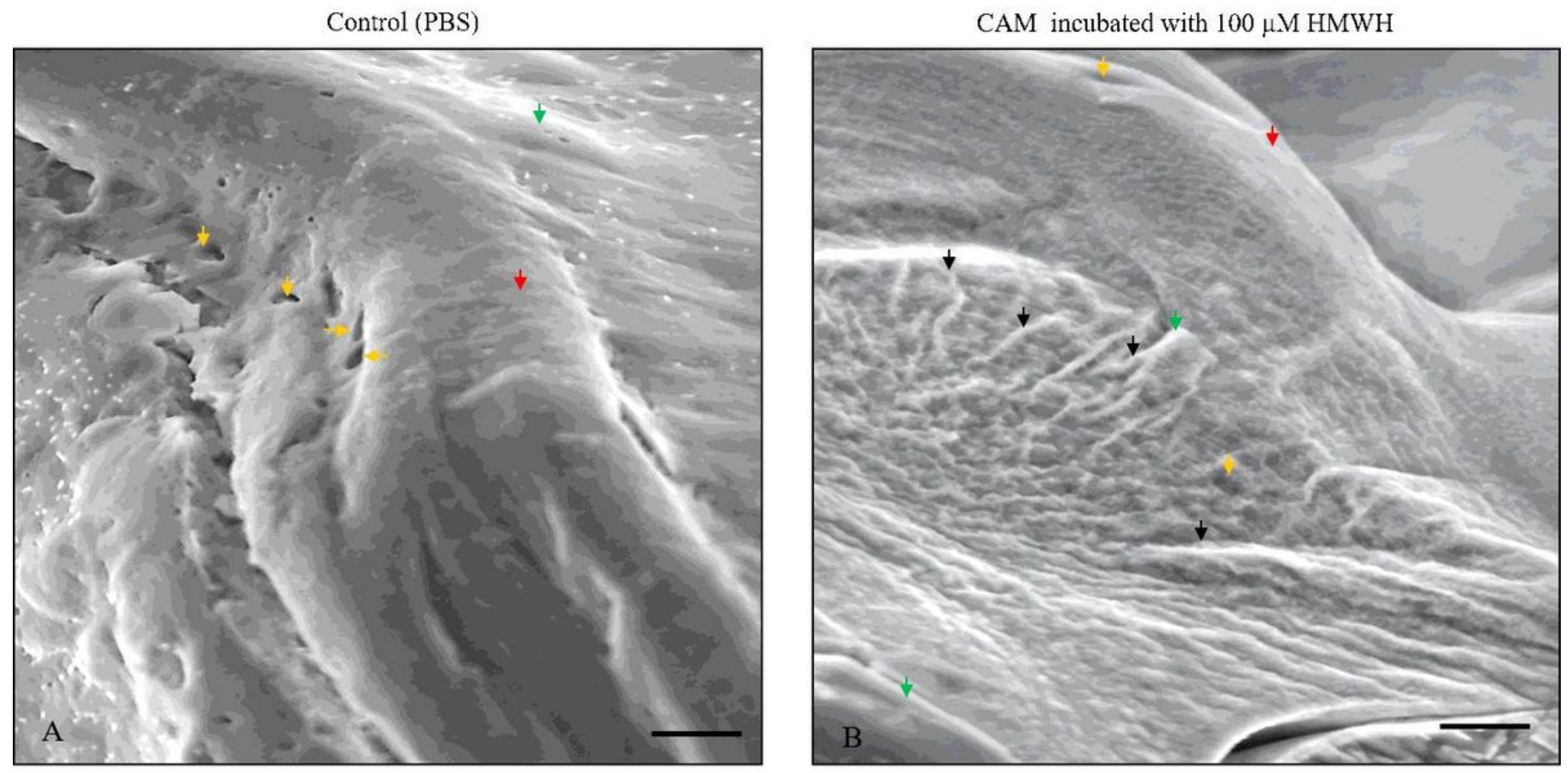

\section{Figure 7}

HMWH modifies the micro-vascular structure of CAM vascular bed. Scanning electron microscopic images of CAM incubated with $100 \mu \mathrm{M}$ concentration of HMWH and control CAM with 1X PBS for 72 hours. CAM incubated with HMWH (Figure 7.B) shows the presence of many sprouted and elongated vessels (black arrows) with a few angiogenic holes (yellow arrows), the capillaries resemble septum-like structures at the vicinity of the giant vessel (red arrow). Control CAM (Figure 7.A) shows a flat capillary network at the outer structure with small blood vessel bulges (green arrows) with many angiogenic holes (yellow arrows) as an indication of intussusceptive angiogenesis for the normal development of CAM vasculature. HMWH has the potential to induce sprouting of new blood vessels from the main vessel through ECs elongation and migration. Images are representative of 3 sets of experiments, and the magnification bar is 200 micrometers.

\section{Supplementary Files}

This is a list of supplementary files associated with this preprint. Click to download.

- ADDITIONALFILE.docx

- HEPARINSUPPLE1.tif

- HEPARINSUPPLE2.png

- HEPARINSUPPLE3.tif 